\title{
Detecting bracoviral orthologs distribution in five tsetse fly species and the housefly genomes
}

\author{
Kelvin M. Kimenyi ${ }^{1}$, Muna F. Abry ${ }^{1}$, Winnie Okeyo ${ }^{2}$, Enock Matovu ${ }^{3}$, Daniel Masiga ${ }^{2}$ \\ and Benard W. Kulohoma ${ }^{1 *}$ (1)
}

\begin{abstract}
Objective: Mutualism between endogenous viruses and eukaryotes is still poorly understood. Several endogenous double-stranded polydnaviruses, bracoviruses, homologous to those present in parasitic braconid wasp genomes were detected in the tsetse fly (Glossina morsitans morsitans). This is peculiar since tsetse flies do not share a reproductive lifestyle similar to wasps, but deliver fully developed larvae that pupate within minutes of exiting their mothers. The objective of this study is to investigate genomic distribution of bracoviral sequences in five tsetse fly species and the housefly, and examine its value as a potential vector control strategy target point. We use comparative genomics to determine the presence, distribution across Glossina species genomes, and evolutionary relationships of bracoviruses of five tsetse fly species and the housefly.
\end{abstract}

Results: We report on homologous bracoviruses in multiple Dipteran genomes. Phylogenetic reconstruction using within-species concatenated bracoviral orthologs shows great congruence with previously reconstructed insect species phylogenies. Our findings suggest that bracoviruses present in Diptera originate from a single integration event of the viral genome that occurred in an ancestor insect before the evolutionary radiation of different insect orders.

Keywords: Bracoviruses, Endogenous viruses, Eukaryotes, Tsetse fly, Housefly

\section{Introduction}

Mutualism between eukaryotes and viruses is rare, since most viruses have parasitic associations with their hosts [1-3]. A group of double-stranded DNA (dsDNA) viruses called polydnaviruses (PDVs) have symbiotic associations with thousands of parasitoid wasps (order Hymenoptera), which parasitize immunocompetent lepidopteran larvae to enable successful reproduction [4]. PDVs have co-evolved with wasps and present a unique opportunity to investigate genome rearrangements associated with these unique mutual symbiotic relationships $[2,5]$.

\footnotetext{
*Correspondence: bkulohoma@uonbi.ac.ke

${ }^{1}$ Centre for Biotechnology and Bioinformatics, University of Nairobi, P.O. Box 30197, Nairobi 00100, Kenya

Full list of author information is available at the end of the article
}

PDVs are broadly classified into two distinctly evolved genera: Bracovirus and Ichnovirus [6, 7]. Bracoviruses are common within a monophyletic group of wasps known as the Microgastroid complex [8]. It is thought that bracoviruses evolved from integration of a nudivirus into the genome of a Microgastroid complex ancestor approximately 100 million years ago (mya) [9]. Mutualism between wasps and bracoviruses developed over time, and functional association is estimated to date back to around $73.7 \pm 10$ mya [10]. Bracoviruses exist in two forms: a linear provirus integrated into the host genome that mediates vertical transmission as Mendelian traits, and as circular dsDNA virions [11, 12]. Viral replication, particle production and packaging into virions occur exclusively in a specialized part of the wasp ovaries (the calyx) [12], and precede injection alongside one or more

(c) The Author(s) 2020. This article is licensed under a Creative Commons Attribution 4.0 International License, which permits use, sharing, adaptation, distribution and reproduction in any medium or format, as long as you give appropriate credit to the original author(s) and the source, provide a link to the Creative Commons licence, and indicate if changes were made. The images or other third party material in this article are included in the article's Creative Commons licence, unless indicated otherwise in a credit line to the material. If material is not included in the article's Creative Commons licence and your intended use is not permitted by statutory regulation or exceeds the permitted use, you will need to obtain permission directly from the copyright holder. To view a copy of this licence, visit http://creativeco mmons.org/licenses/by/4.0/. The Creative Commons Public Domain Dedication waiver (http://creativecommons.org/publicdomain/ zero/1.0/) applies to the data made available in this article, unless otherwise stated in a credit line to the data. 
wasp eggs into the parasitized caterpillar host during wasp oviposition [13]. Virions are replication deficient and their dsDNA is only expressed by the caterpillar host's cellular replication machinery $[6,14]$. The virion particles encode proteins that compromise the caterpillar host immune defense, thus preventing recognition, encapsulation and destruction of the parasitoid eggs and larvae $[9,15]$. However, lack of genes that independently encode viral structural proteins has elicited a debate on whether bracoviruses are of viral origin or a 'genetic secretion' of the wasps [12]. An example is the bracoviral virion DNA in the wasp Cotesia congregata that consists of cellular genes of wasp origin, several viral genes and transposable elements [15]. Phylogenetic analysis of its functional bracoviral genes has highlighted sugar transporters of wasp origin [11]. Transfer of these wasp genes into the provirus was facilitated by transposable elements, and subsequently followed by co-evolution with the host's genome, to become more specialized $[2,5,9]$.

\section{Main text}

The recently sequenced genome of the tsetse fly, Glossina morsitans morsitans (order Diptera), has revealed numerous homologous bracoviral genes $(\mathrm{n}=305)$, widely spread across the genome; in addition to a large DNA hytrosavirus, the Glossina pallidipes salivary gland hypertrophy virus (GpSGHV) [16]. Although GpSGHV has been associated with reduced fecundity, life span, and causes salivary gland pathology in Glossina, its value as a potential entry point as a tsetse fly control strategy is has to-date not been explored. Perhaps more interesting is the finding of bracoviral sequences that bear close similarity (Basic Local Alignment Search Tool (BLAST), $E$ values of $<1 \mathrm{e}-50)$ to those identified in the parasitic wasps (order Hymenoptera) Glyptapanteles flavicoxis and Cotesia congregata, where they occur as PDVs [2, 16]. Although the role of PDVs is well characterized in parasitic wasps, their organization, composition and functions in the tsetse fly genome is not known; indeed, their presence is new information. Molecular dating estimates that the orders Diptera (includes the tsetse fly and the house fly) and Hymenoptera (includes wasps) diverged 350 mya [8], which is prior to the estimated date of first integration of bracoviruses into the ancestral wasp genome [9]. This raises the possibility that these genes may be remnants of PDVs acquired before this separation, and tsetse flies lost bracoviral mutualism after they adapted to larviparity (development of a single larva in its uterus as opposed to laying multiple eggs). An alternate hypothesis is that an undetermined braconid wasp may have parasitized the tsetse fly ancestor [16].

Tsetse flies are important vectors that transmit African trypanosomiasis to humans (sleeping sickness) and cattle (nagana). Approximately 70 million people and 50 million cattle are at risk of disease in tsetse-fly infested areas [17]. There are limited strategies for trypanosomiasis management primarily resulting from undesirable side effects of trypanocidal drug treatments; and there are emerging reports of multi-drug resistance [18-21]. According to the Pan African Tsetse and Trypanosomiasis Eradication Campaign (PATTEC), eradicating tsetse populations is the most viable approach of controlling trypanosomiasis in sub-Saharan Africa [22]. Identification of Glossina genes regulating vectorial capacity is thus a priority, as their manipulation would provide important clues for the development of effective vector control strategies, which will greatly facilitate trypanosomiasis control [18]. The tsetse fly, unlike other members of the order Diptera, does not lay eggs, but bears a fully developed larva (obligate adenotrophic viviparity) [23]. This makes it challenging to study PDVs in Glossina since during tsetse fly reproduction they are not replicated, excised from the host insect genome and packaged into viral particles that are mixed with semen like in parasitoid wasps. Wasp PDVs can easily be studied by first specifically extracting viral particles from the host [6]. Moreover, most bracoviruses consist of genes of host cell origin with protein domains conserved across metazoans, which further complicates analysis [24].

In this study, we aimed to identify polydnaviruses (PDVs) present in five recently sequenced tsetse fly genomes (G. austeni, G. brevipalpis, G. fuscipes, G. m. morsitans, and G. pallidipes) and the housefly (Musca domestica) [16, 25], by using references described in three parasitoid wasps (Cotesia sesamiae Mombasa bracovirus, Cotesia congregata, and Glyptapanteles flavicoxis) [26].

\section{Methods}

\section{Identification of bracoviral orthologs}

The proteomes of G. austeni, G. brevipalpis, G. fuscipes, G. m. morsitans, G. pallidipes, and M. domestica were retrieved from VectorBase (www.vectorbase.org) [27]. Bracoviral orthologs $(\mathrm{n}=305)$ present in the G. m. morsitans proteome, previously described by the International Glossina Genome Initiative [16], were retrieved using a Perl script and used as sequence data references, in both nucleic and amino acid format (VectorBase assembly: GmorY1). The retrieved proteomes alongside previously described reference sequences were assigned to homologous clusters using OrthoMCL with default settings (BLASTP E-value cut-off $1 \mathrm{e}-5$ and inflation index 2.5) [28]; using the G. m. morsitans proteome bracoviral orthologs $(n=305)$. Mapped orthologs were subsequently processed using BMX, as described in detail elsewhere [29-31]. 
Sequence alignment and phylogeny reconstruction

Multiple sequence alignments were performed using MUSCLE [32]. Maximum likelihood (ML) phylogenetic analysis of the multiple aligned sequences with bootstrap values of 100 replicates was performed using PHYML version 3.520 [33]. Phylogenetic reconstruction using species-specific concatenated bracoviral orthologs was preceded by aligning sequences within individual ortholog cluster files to ensure joined sequences were of the same length.

\section{Results}

We identified 53 bracoviral ortholog clusters, and a total of 2020 orthologs present across five Glossina species and $M$. domestica genomes (Fig. 1). The distribution varied across species: G. austeni $(\mathrm{n}=333)$, G. brevipalpis $(\mathrm{n}=303)$, G. fuscipes $(\mathrm{n}=334)$, G. morsitans $(\mathrm{n}=304), \mathrm{G}$. pallidipes $(n=332)$, and $M$. domestica $(n=414)$. Most of the identified orthologs were homologous to those present in Glyptapanteles indiensis $(\mathrm{n}=603)$ and Glyptapanteles flavicoxis $(\mathrm{n}=1109)$. The protein kinase cluster had the most abundant number of orthologs $(n=286)$ (Fig. 1a), which were all homologous to those present in either Glyptapanteles indiensis or Glyptapanteles flavicoxis (Fig. 1b). We then established evolutionary relationships of bracoviral orthologs identified in the five Glossina species and M. domestica genomes by phylogenetic reconstruction using species-specific concatenated bracoviral orthologs. This revealed congruence with previously reconstructed insect species phylogenies [34]; tsetse fly species in the same group clustered closely together (Fig. 2). Interestingly, the concatenated bracoviral orthologs from G. m. morsitans appeared to be more distant to those from G. brevipalpis (same genus), compared to the distance to M. domestica (same order).

\section{Discussion}

Bracovirus represent a unique symbiotic relationship between eukaryotes and endogenous viruses. Endogenous bracoviral sequences identified in the genomes of parasitoid wasps, some moth and butterfly lineages, and Glossina morsitans morsitans are plausibly due to rearrangements of ancient integrations. [12, 16, 35, 36].

We identified orthologs of polydnaviruses (PDVs) in recently sequenced G. austeni, G. brevipalpis, G. fuscipes, G. pallidipes, and M. domestica genomes. Although bracoviruses in wasps are co-opted to ensure their successful reproduction, their role in Diptera that do not share this mode of reproduction was unclear. Our findings suggest that PDVs are descended from a single ancestor after

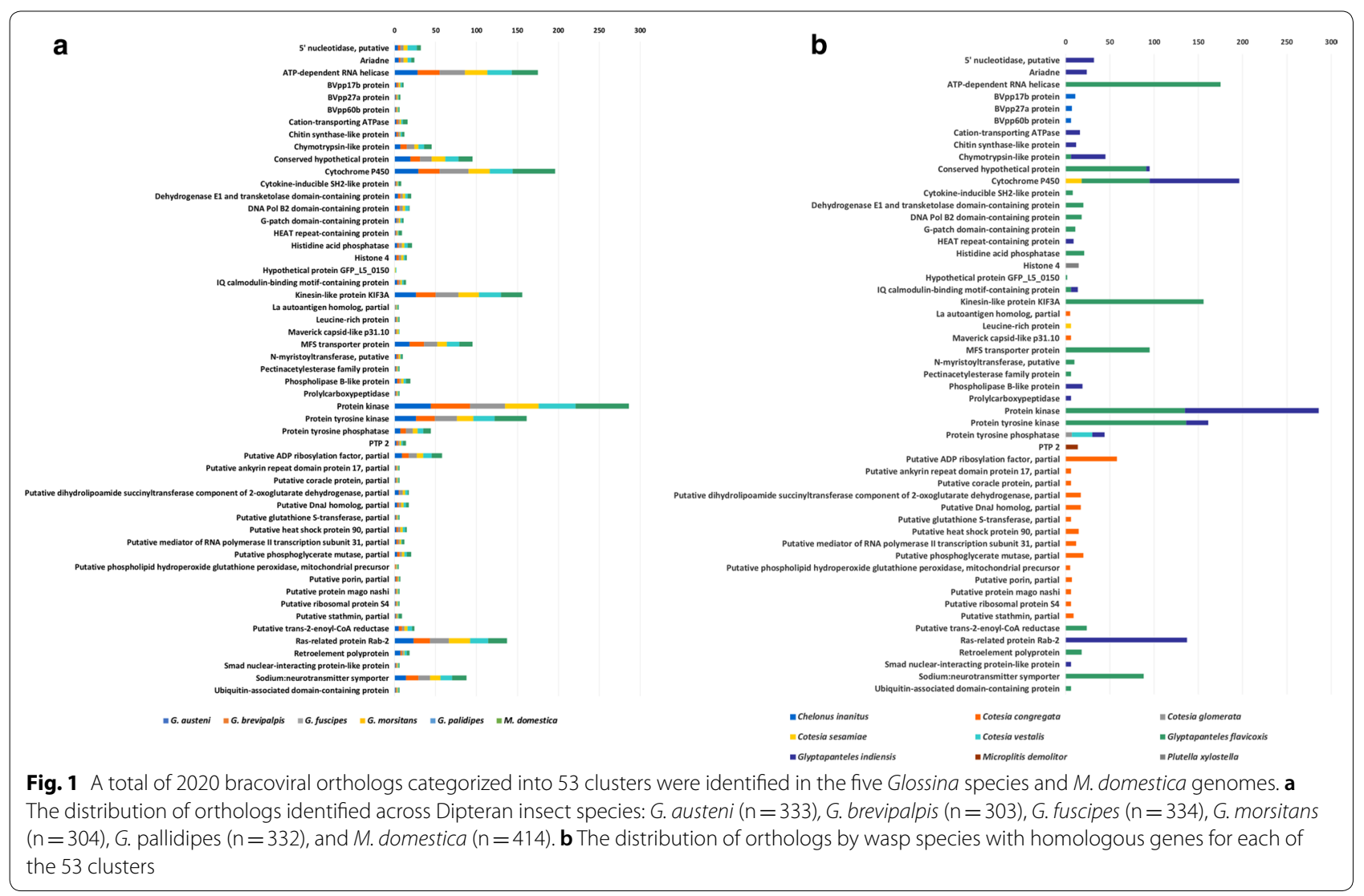




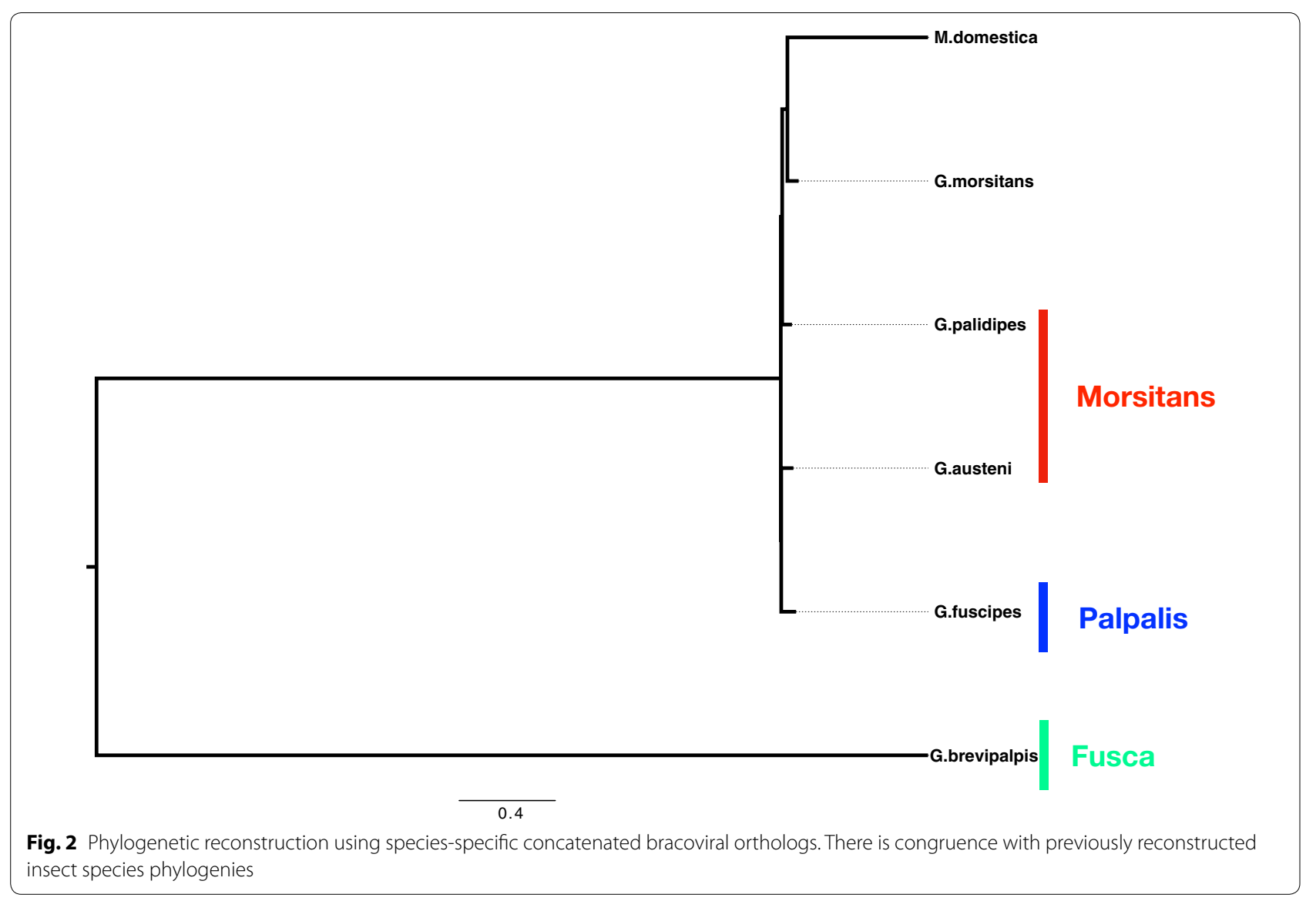

initial host integration before the evolutionary radiation of different insect orders, and their presence in the reference G. $m$. morsitans is not a single random genetic introgression event. It is unclear when exactly parasitoid wasp and Dipteran PDVs separated and diversified in their different hosts. Our findings support previous suggestions that bracoviruses are descended from a common ancestor in the Paleozoic Era, and raise the possibility of integration of PDVs before the separation of Hymenoptera, Coleoptera, Lepidoptera and Diptera [8]. We also show that PDVs vary in size and display phylogenetic diversity, which suggests intra-genomic PDVs rearrangements while co-evolving with the specific host's genome to adapt to different environments. PDVs progressively decay after integration, with minimal effects on the host's fitness, as they evolve blurring genetic detection [36, 37]. Fine-scale analyses of genetic variation underscore retention of adaptive alleles and loss of non-adaptive genes mediated through selection pressure at bracoviral genes [38]. Accumulation of mutations, recombination, and/or deletions leads to dissolution of bracoviral genes in the host genome, and genes that acquire function for the host are under positive selection [36]. PDVs that coevolve with the recipient insect genome to provide new physiological function must adapt to the eukaryotic expression machinery [12, 35, 36]. Phylogeny reconstruction using concatenated within-species PDVs showed congruence with previously reconstructed insect species phylogenies [34], suggesting that adaptive bracoviral evolution within the order Diptera is associated with the host insect's environment. It is intriguing to note that $G$. m. morsitans is more distant to G. brevipalpis than the housefly, which is of a different genus. G. brevipalpis is closest to the root, implying that its PDVs are the least diverse.

Understanding the genetic composition and organization of bracoviruses has led to new vector control strategies using transgenic approaches [12]. For example, the polydnavirus Oryctes rhinoceros nudivirus (OrNV) has been used as a biological control agent in palm tree farming against the rhinocerous beetle [12]. Successful delivery of bracoviral genes by wasps into lepidopteran larvae has also inspired notable agricultural applications. Currently, teratocyte secretory protein (TSP14) producing transgenic plants effectively reduce Manduca sexta growth and development, thus protecting the plants from insect damage [39]. Detrimental agricultural effects have also been observed, for example acquisition of 
horizontally transferred genes by lepidopterans, braconid wasps, and mites that detoxify inhibitory alkaloids and cyanide have increased pest fitness allowing to overcome plant defences produced upon attack [36, 40]. Our findings suggest that the presence of bracoviruses is neither a result of a pathogenic virus contamination of the reference Glossina morsitans genome, nor a single case of being parasitized by bracoviruses of wasp origin. This newfound knowledge provides better understanding of tsetse biology, and highlights possible novel intervention target points.

\section{Limitations}

The limitation in this study was the absence of laboratory experimental validation using PCR of identified bracoviral sequences to those previously established in wasps. We anticipate that this would refine the number of orthologs to a smaller set of bracoviral homologs found in wasps. We were able to partly circumvent this challenge by using very stringent BLAST p-values (BLASTP E-value cut-off $1 \mathrm{e}-5$ and inflation index 2.5).

\section{Abbreviations \\ DNA: Deoxyribonucleic acid; dsDNA: Double-stranded DNA; GpSGHV: Glossina pallidipes salivary gland hypertrophy virus; BLAST: Basic Local Alignment Search Tool; PCR: Polymerase chain reaction; PDVs: Polydnaviruses; OrNV: Oryctes rhinoceros nudivirus; TSP14: Teratocyte secretory protein; PATTEC: Pan African Tsetse and Trypanosomiasis Eradication Campaign.}

\section{Acknowledgements}

We would like to thank Prof. John Chisi from the College of Medicine, University of Malawi who provided G. m. morsitans from Malawi, and support from the University of Nairobi's Centre for Biotechnology and Bioinformatics and ICIPE.

\section{Authors' contributions \\ BWK and DM conceived and designed the study. KMK, WO, BWK performed experiments and analysis. DM and EM obtained samples. BWK, KMK, MAF, WO, EM, and DM wrote the initial manuscript draft. KMK, MAF, WO, EM, DM and BWK wrote the final version of the manuscript. All authors read and approved the final manuscript.}

\section{Funding}

The work was supported by the Wellcome Trust [087540] through a pumppriming grant to BWK from the Training Health Researchers into Vocational Excellence in East Africa (THRiVE) Initiative. We gratefully acknowledge funding to icipe by the following organizations and agencies: UK's Department for International Development (DFID); Swedish International Development Cooperation Agency (Sida); the Swiss Agency for Development and Cooperation (SDC); the governments of Kenya and Ethiopia. The funders had no role in study design, data collection and analysis, decision to publish, or preparation of the manuscript.

\section{Availability of data and materials}

All materials and data used to perform this study are available in the main text. Raw sequence data used for analysis in publicly available at VectorBase (https ://www.vectorbase.org/) with the following Gene set accession identities: Musca domestica (MdomA1.3), Glossina morsitans (GmorY1.9), Glossina austeni (GausT1.7), Glossina brevipalpis (Gbrel1.7), Glossina fuscipes (Gfusl1.7), and Glossina pallidipes (Gpall1.7). Orthologous reference sequences used (Chelonus inanitus, Cotesia congregata, Cotesia congregata bracovirus, Cotesia glomerata bracovirus, Cotesia sesamiae Mombasa bracovirus, Cotesia vestalis bracovirus,
Glyptapanteles flavicoxis, Glyptapanteles indiensis, Microplitis demolitor bracovirus, Plutella xylostella) were first detected in G. morsitans and are available at PMID:24763584 or https://doi.org/10.1126/science.1249656.

\section{Ethics approval and consent to participate}

This research entails analysis of secondary data, and does not involve human participants, human material, or human data.

\section{Consent for publication}

Not applicable.

\section{Competing interests}

The authors declare no competing interest.

\section{Author details}

${ }^{1}$ Centre for Biotechnology and Bioinformatics, University of Nairobi, P.O. Box 30197, Nairobi 00100, Kenya. ${ }^{2}$ International Centre of Insect Physiology and Ecology, P.O. Box 30772, Nairobi 00100, Kenya. ${ }^{3}$ Makerere University, P.O. Box 7062, Kampala, Uganda.

Received: 13 March 2020 Accepted: 27 June 2020

Published online: 02 July 2020

\section{References}

1. Burke GR, Walden KK, Whitfield JB, Robertson HM, Strand MR. Widespread genome reorganization of an obligate virus mutualist. PLOS Genet. 2014;10(9):e1004660.

2. Espagne E, Dupuy C, Huguet E, Cattolico L, Provost B, Martins N, Poirie M, Periquet G, Drezen JM. Genome sequence of a polydnavirus: insights into symbiotic virus evolution. Science (New York, NY). 2004;306(5694):286-9.

3. Federici BA, Bigot Y. Origin and evolution of polydnaviruses by symbiogenesis of insect DNA viruses in endoparasitic wasps. J Insect Physiol. 2003:49(5):419-32.

4. Strand MR, Burke GR. Polydnaviruses as symbionts and gene delivery systems. PLoS Pathog. 2012;8(7):e1002757.

5. Jancek S, Bezier A, Gayral P, Paillusson C, Kaiser L, Dupas S, Le Ru BP, Barbe $V$, Periquet $G$, Drezen JM, et al. Adaptive selection on bracovirus genomes drives the specialization of Cotesia parasitoid wasps. PLoS ONE. 2013;8(5):e64432.

6. Bezier A, Louis F, Jancek S, Periquet G, Theze J, Gyapay G, Musset K, Lesobre J, Lenoble P, Dupuy C, et al. Functional endogenous viral elements in the genome of the parasitoid wasp Cotesia congregata: insights into the evolutionary dynamics of bracoviruses. Philos Trans R Soc Lond B Biol Sci. 2013:368(1626):20130047.

7. Gundersen-Rindal DE, Pedroni MJ. Characterization and transcriptional analysis of protein tyrosine phosphatase genes and an ankyrin repeat gene of the parasitoid Glyptapanteles indiensis polydnavirus in the parasitized host. J General Virol. 2006;87(Pt 2):311-22.

8. Theze J, Bezier A, Periquet G, Drezen JM, Herniou EA. Paleozoic origin of insect large dsDNA viruses. Proc Natl Acad Sci USA. 2011;108(38):15931-5.

9. Herniou EA, Huguet E, Theze J, Bezier A, Periquet G, Drezen JM. When parasitic wasps hijacked viruses: genomic and functional evolution of polydnaviruses. Philos Trans R Soc Lond B Biol Sci. 2013;368(1626):20130051.

10. Whitfield JB. Estimating the age of the polydnavirus/braconid wasp symbiosis. Proc Natl Acad Sci USA. 2002;99(11):7508-13.

11. Desjardins CA, Gundersen-Rindal DE, Hostetler JB, Tallon LJ, Fuester RW, Schatz MC, Pedroni MJ, Fadrosh DW, Haas BJ, Toms BS, et al. Structure and evolution of a proviral locus of Glyptapanteles indiensis bracovirus. BMC Microbiol. 2007;7:61.

12. Bezier A, Annaheim M, Herbiniere J, Wetterwald C, Gyapay G, BernardSamain S, Wincker P, Roditi I, Heller M, Belghazi M, et al. Polydnaviruses of braconid wasps derive from an ancestral nudivirus. Science (New York, NY). 2009;323(5916):926-30.

13. Louis F, Bezier A, Periquet G, Ferras C, Drezen JM, Dupuy C. The bracovirus genome of the parasitoid wasp Cotesia congregata is amplified within 13 replication units, including sequences not packaged in the particles. $J$ Virol. 2013;87(17):9649-60.

14. Chevignon G, Theze J, Cambier S, Poulain J, Da Silva C, Bezier A, Musset K, Moreau SJ, Drezen JM, Huguet E. Functional annotation of Cotesia 
congregata bracovirus: identification of viral genes expressed in parasitized host immune tissues. J Virol. 2014;88(16):8795-812.

15. Drezen JM, Bezier A, Lesobre J, Huguet E, Cattolico L, Periquet G, Dupuy C. The few virus-like genes of Cotesia congregata bracovirus. Arch Insect Biochem Physiol. 2006;61(3):110-22.

16. International Glossina Genome Initiative. Genome sequence of the tsetse fly (Glossina morsitans): vector of African trypanosomiasis. Science (New York, NY). 2014;344(6182):380-6.

17. Simarro PP, Cecchi G, Franco JR, Paone M, Diarra A, Ruiz-Postigo JA, Fevre EM, Mattioli RC, Jannin JG. Estimating and mapping the population at risk of sleeping sickness. PLoS Neglected Trop Dis. 2012;6(10):e1859.

18. Barrett MP, Boykin DW, Brun R, Tidwell RR. Human African trypanosomiasis: pharmacological re-engagement with a neglected disease. $\mathrm{Br} J$ Pharmacol. 2007;152(8):1155-71.

19. Brun R, Blum J, Chappuis F, Burri C. Human African trypanosomiasis. Lancet. 2010;375(9709):148-59.

20. Wamwenje SAO, Wangwe II, Masila N, Mirieri CK, Wambua L, Kulohoma BW. Community-led data collection using Open Data Kit for surveillance of animal African trypanosomiasis in Shimba hills, Kenya. BMC Res Notes. 2019;12(1):151.

21. Wangwe I, Wamwenje SA, Mirieri C, Masila NM, Wambua L, Kulohoma BW. Modelling appropriate use of trypanocides to restrict wide-spread multidrug resistance during chemotherapy of animal African trypanosomiasis. Parasitology. 2019;146(6):774-80.

22. Solano P, Ravel S, de Meeûs T. How can tsetse population genetics contribute to African trypanosomiasis control? Trends Parasitol. 2010;26:255-63.

23. Benoit JB, Attardo GM, Baumann AA, Michalkova V, Aksoy S. Adenotrophic viviparity in tsetse flies: potential for population control and as an insect model for lactation. Annu Rev Entomol. 2015;60:351-71.

24. Bezier A, Herbiniere J, Serbielle C, Lesobre J, Wincker P, Huquet E, Drezen JM. Bracovirus gene products are highly divergent from insect proteins. Arch Insect Biochem Physiol. 2008;67(4):172-87.

25. Scott JG, Warren WC, Beukeboom LW, Bopp D, Clark AG, Giers SD, Hediger M, Jones AK, Kasai S, Leichter CA, et al. Genome of the house fly, Musca domestica L., a global vector of diseases with adaptations to a septic environment. Genome Biol. 2014;15(10):466.

26. Dupuy C, Periquet G, Serbielle C, Bezier A, Louis F, Drezen JM. Transfer of a chromosomal Maverick to endogenous bracovirus in a parasitoid wasp. Genetica. 2011;139(4):489-96.

27. Giraldo-Calderon Gl, Emrich SJ, MacCallum RM, Maslen G, Dialynas E, Topalis P, Ho N, Gesing S, VectorBase C, Madey G, et al. VectorBase: an updated bioinformatics resource for invertebrate vectors and other organisms related with human diseases. Nucleic Acids Res. 2015;43:D707-13 (Database issue).
28. Li L, Stoeckert CJ Jr, Roos DS. OrthoMCL: identification of ortholog groups for eukaryotic genomes. Genome Res. 2003;13(9):2178-89.

29. Abry MF, Kimenyi KM, Masiga D, Kulohoma BW. Comparative genomics identifies male accessory gland proteins in five Glossina species. Wellcome Open Res. 2017;2:73.

30. Abry MF, Kimenyi KM, Osowo FO, Odhiambo WO, Sewe SO, Kulohoma BW. Genetic diversity of the Pneumococcal CbpA: implications for next-generation vaccine development. Human Vaccines Immunother. 2015;11:1261

31. Kulohoma BW. BMX: a tool for computing bacterial phyletic composition from orthologous maps. BMC Res Notes. 2015;8:51.

32. Edgar RC. MUSCLE: multiple sequence alignment with high accuracy and high throughput. Nucleic Acids Res. 2004;32(5):1792-7.

33. Guindon S, Gascuel O. A simple, fast, and accurate algorithm to estimate large phylogenies by maximum likelihood. Syst Biol. 2003;52(5):696-704.

34. Chen X, Li S, Aksoy S. Concordant evolution of a symbiont with its host insect species: molecular phylogeny of genus Glossina and its bacteriome-associated endosymbiont, Wigglesworthia glossinidia. J Mol Evol. 1999;48(1):49-58.

35. Desjardins CA, Gundersen-Rindal DE, Hostetler JB, Tallon LJ, Fadrosh DW, Fuester RW, Pedroni MJ, Haas BJ, Schatz MC, Jones KM, et al. Comparative genomics of mutualistic viruses of Glyptapanteles parasitic wasps. Genome Biol. 2008;9(12):R183.

36. Drezen JM, Josse T, Bezier A, Gauthier J, Huguet E, Herniou EA. Impact of lateral transfers on the genomes of lepidoptera. Genes (Basel). 2017:8(11):315.

37. Langley $\mathrm{CH}$, Charlesworth B. Endogenous proviruses as "mementos"? Nature. 1997;388(6645):840.

38. Gauthier J, Gayral P, Le Ru BP, Jancek S, Dupas S, Kaiser L, Gyapay G, Herniou EA. Genetic footprints of adaptive divergence in the bracovirus of Cotesia sesamiae identified by targeted resequencing. Mol Ecol. 2018;27(8):2109-23

39. Maiti IB, Dey N, Pattanaik S, Dahlman DL, Rana RL, Webb BA. Antibiosistype insect resistance in transgenic plants expressing a teratocyte secretory protein (TSP14) gene from a hymenopteran endoparasite (Microplitis croceipes). Plant Biotechnol J. 2003;1(3):209-19.

40. Tan CW, Peiffer M, Hoover K, Rosa C, Acevedo FE, Felton GW. Symbiotic polydnavirus of a parasite manipulates caterpillar and plant immunity. Proc Natl Acad Sci USA. 2018;115(20):5199-204.

\section{Publisher's Note}

Springer Nature remains neutral with regard to jurisdictional claims in published maps and institutional affiliations.
Ready to submit your research? Choose BMC and benefit from:

- fast, convenient online submission

- thorough peer review by experienced researchers in your field

- rapid publication on acceptance

- support for research data, including large and complex data types

- gold Open Access which fosters wider collaboration and increased citations

- maximum visibility for your research: over $100 \mathrm{M}$ website views per year

At BMC, research is always in progress.

Learn more biomedcentral.com/submissions 